\title{
SMARCC1 expression is positively correlated with pathological grade and good prognosis in renal cell carcinoma
}

\author{
Gangmin Wang ${ }^{1 \#}$, Qi Lv ${ }^{2 \#}$, Chunhui $\mathrm{Ma}^{3}$, Yinan Zhang ${ }^{4}$, Haoming Li ${ }^{5}$, Qiang Ding ${ }^{1}$ \\ ${ }^{1}$ Department of Urology, Huashan Hospital, Fudan University, Shanghai, China; ${ }^{2}$ Imaging Department of Tongji Hospital, Medical School of Tongji \\ University, Shanghai, China; ${ }^{3}$ Department of Orthopedic Surgery, Shanghai General Hospital, Shanghai Jiaotong University, Shanghai, China; \\ ${ }^{4}$ Department of Urology, Shandong Province Affiliated Hospital, Shandong University, Jinan, China; ${ }^{5}$ Department of Human Anatomy, Medical \\ School of Nantong University, Nantong, China \\ Contributions: (I) Conception and design: Q Ding; (II) Administrative support: None; (III) Provision of study materials or patients: Y Zhang, G Wang, \\ Q Lv; (IV) Collection and assembly of data: C Ma, Q Lv; (V) Data analysis and interpretation: H Li, G Wang; (VI) Manuscript writing: All authors; \\ (VII) Final approval of manuscript: All authors. \\ \#These authors contributed equally to this work. \\ Correspondence to: Qiang Ding. Department of Urology, Huashan Hospital, Fudan University, No. 12, Middle Urumqi Road, Jing'an District, \\ Shanghai 200040, China. Email: 393212347@qq.com.
}

\begin{abstract}
Background: Renal cell carcinoma (RCC), which is derived from the renal tubular epithelium, is now the most common urological cancer. Of the four RCC subtypes, clear cell RCC (ccRCC) is the most common subtype and accounts for $75-80 \%$ of all RCC cases. SMARCC1, also known as BAF155, together with SMARCA4, SMARCA2, and SMARCB1, comprises the SWI/SNF protein family. It has been reported that the expression of SMARCC1 was correlated with some human cancers including prostate cancer, colon cancer, and pancreatic cancer. However, the mechanisms and regulatory roles of SMARCC1 in ccRCC are not well defined.
\end{abstract}

Methods: Our current study primarily investigated the expression of SMARCC1 and its clinical importance in two common histological types of ccRCC using microarrays (HKidE180Su02, MecDNAHKidE030CS01).

Results: The results showed that the expression of SMARCC1 in ccRCC tissues was significantly decreased compared with that in corresponding para-tumor tissue $(4.370 \pm 2.036$ vs. $6.167 \pm 1.162, \mathrm{P}=0.001)$. SMARCC1 expression was positively correlated with pathological grade $(\mathrm{r}=0.224, \mathrm{P}=0.011)$. Moreover, ccRCC patients with high SMARCC1 expression had a better prognosis than those with low SMARCC1 expression (40.0\% vs. $95.2 \%, \mathrm{P}=0.000)$ in the following sub-groups: pathological grade (III and IV), male sex (73.5\% vs. $95.3 \%$, $\mathrm{P}=0.004)$, and tumor size $>5 \mathrm{~cm}(62.5 \%$ vs. $89.5 \%, \mathrm{P}=0.044)$.

Conclusions: A further study is necessary to explain the mechanism of the occurrence and progression of ccRCC.

Keywords: SMARCC1; prognosis; renal cell carcinoma (RCC)

Submitted May 19, 2020. Accepted for publication Oct 28, 2020.

doi: 10.21037/tau-20-935

View this article at: http://dx.doi.org/10.21037/tau-20-935

\section{Introduction}

Chromatin remodeling is an important aspect of epigenetics, as it regulates DNA replication, repair, and recombination through dynamic structural changes in chromatin. SMARCC1, also known as BAF155, together with SMARCA4, SMARCA2, and SMARCB1, comprises the SWI/SNF protein family (1). SMARCC1 functions as a helicase and ATPase that can regulate the transcription of certain genes by changing the chromatin structure around these genes. SMARCC1 is part of the ATP-dependent SWI/ 
SNF chromatin remodeling complex and contains a leucine zipper motif that binds to many typical transcription factors. It has been reported that the expression of SMARCC1 is correlated with some human cancers including prostate cancer, colon cancer, and pancreatic cancer $(2,3)$. For example, the expression of SMARCC1 was shown to be upregulated and positively correlated with tumor recurrence and dedifferentiation in prostate cancer $(3,4)$. MicroRNA202-5p targets SMARCC1 and acts as a tumor suppressor in colorectal carcinoma (5). In addition, SMARCC1 expression mediates drug resistance in pancreatic cancer cells and is regulated by miR-320c (6). We present the following article in accordance with the REMARK reporting checklist (available at http://dx.doi.org/10.21037/tau-20-935).

Renal cell carcinoma (RCC), which is derived from the renal tubular epithelium, is the most common urological cancer (7). The four common subtypes of RCC are as follows: clear cell RCC (ccRCC), papillary RCC (PRCC), chromophobe RCC (ChRCC), and collecting duct carcinoma. ccRCC accounts for as many as $75-80 \%$ of all RCC cases, whereas the other three subtypes of PRCC, ChRCC, and collecting duct carcinoma account for the other $20-25 \%$ of RCC cases (8-11). In 2018, it was reported that mutations in or loss of SMARCC1 are associated with the dedifferentiation subsets of RCC (9). However, the mechanisms and regulatory roles of SMARCC1 in ccRCC require further research.

The aim of our study was to explore the expression of SMARCC1 in ccRCC as well as the correlation between SMARCC1 expression and the clinical parameters and overall survival of patients with ccRCC.

\section{Methods}

\section{Clinical materials}

All 150 patients were diagnosed with ccRCC based on the World Health Organization/International Society of Urological Pathology (WHO/ISUP) classification system of renal cell tumors. All included patients in this study received no extra therapy from February 2008 to September 2010 before surgery, and were followed up after surgery until August 2015. All the patients with ccRCC were graded using the WHO/ISUP grading system and divided into two groups by tumor pathology: the clear cell renal carcinoma group and the clear cell renal carcinoma group with other pathological types (clear cell carcinoma with sarcomatoid degeneration, clear cell carcinoma with PRCC, and clear cell carcinoma with ChRCC). In addition, all the patients were divided into several sub-groups by gender (male or female), pathological grade (low pathological grade: grades I and II, high pathological grade: grades III and IV), and tumor size $(\leq 5$ or $>5 \mathrm{~cm})$. The American Joint Committee on Cancer (AJCC) 7th Edition Cancer Staging System was used for all included cases in this study. The clinical characteristics of patients were described in detail in Table 1. The study was conducted in accordance with the Declaration of Helsinki (as revised in 2013). Informed consent was obtained, and the study was approved by The Ethics Boards of Huashan Hospital (No. 2020 529). All experiments were carried out in accordance with institutional guidelines. Written informed consent was obtained from the patients undergoing surgery.

\section{Tissue microarray}

A kidney cancer tissue microarray (HKidE180Su02, Shanghai Outdo Biotech Co., Ltd.), was used to explore the expression of SMARCC1 in ccRCC patients and its impact on survival of ccRCC patients. The tissue microarray included 150 cancer tissues and 30 adjacent tissues $(1.5 \mathrm{~cm}$ away from the carcinoma) from ccRCC patients. The tissue microarray was made by using a core needle to punch a core column from the wax block with a fixed diameter of $1.5 \mathrm{~mm}$. The tissue cores were selected from most high-grade areas of tumor, and 128 cores were taken from tumor and normal renal parenchyma. After the array block was completed, $4 \mu \mathrm{m}$ slices were cut out.

\section{Immunobistochemistry}

The tissue sections were subjected to antigen retrieval using EDTA buffer at high temperature and high pressure. Then, the sections were incubated with a primary rabbit polyclonal antibody against SMARCC1 (1:10,000, Abcam, $\mathrm{AB} 22355)$ at $4{ }^{\circ} \mathrm{C}$ overnight. The sections were then incubated with an HRP-labeled anti-mouse secondary antibody (DAKO). After washes in PBS and visualization with diaminobenzidine and hematoxylin counterstain, the sections were observed and analyzed under a microscope.

Each section was scored and grouped according to positive staining intensity and percentage of cells stained. According to the proportion of positively stained cancer cells, the percentage of positively stained cells by IHC was defined as follows: "Negative" received a score of 0 , " $0-1 \%$ " indicated a score of 1 , " $21-40 \%$ " a score of 2, " $41-60 \%$ " a 
Table 1 Detailed clinical information of the clear cell renal cell carcinoma (ccRCC) patients

\begin{tabular}{|c|c|c|c|}
\hline Clinical index & $\mathrm{N}$ & Lost & Total N \\
\hline Gender & & 0 & 150 \\
\hline Male & 107 & & \\
\hline Female & 43 & & \\
\hline Age & & 0 & 150 \\
\hline$\leq 60$ years & 95 & & \\
\hline$>60$ years & 55 & & \\
\hline Tumor size & & 0 & 150 \\
\hline$\leq 5 \mathrm{~cm}$ & 94 & & \\
\hline$>5 \mathrm{~cm}$ & 56 & & \\
\hline T stage & & 0 & 150 \\
\hline $\mathrm{T} 1$ & 122 & & \\
\hline T2-T3 & 28 & & \\
\hline $\mathrm{N}$ stage & & 0 & 150 \\
\hline NO & 147 & & \\
\hline $\mathrm{N} 1$ & 3 & & \\
\hline M stage & & 0 & 150 \\
\hline \multicolumn{4}{|l|}{ Mo } \\
\hline M1 & 2 & & \\
\hline Clinical stage & & 0 & 150 \\
\hline Stage I & 122 & & \\
\hline Stage II & 16 & & \\
\hline Stage III & 11 & & \\
\hline Stage IV & 1 & & \\
\hline Pathological grade & & 0 & 150 \\
\hline I-II & 103 & & \\
\hline III & 47 & & \\
\hline Groups & & 0 & 150 \\
\hline Clear cell renal cell carcinomas & 136 & & \\
\hline $\begin{array}{l}\text { Clear cell renal carcinoma group } \\
\text { with other pathological types }\end{array}$ & 14 & & \\
\hline
\end{tabular}

score of 3, "61-80\%" a score of 4, and " $81-100 \%$ " a score of 5 . The scores for staining intensity were as follows: "Negative" received a score of 0 , " $1+$ " indicated a score of 1, " $2+$ " a score of 2 , and " $3+$ " a score of 3 . Patients were divided into two groups according to the total score, which was obtained by multiplying the "positive staining rate score" and the "staining intensity score". Samples with scores $\leq 2.5$ were considered the low expression group, whereas samples with scores $>2.5$ were considered the high expression group. The negative control was included by adding PBS instead of the primary antibody.

\section{qRT-PCR}

A total of 30 tissue samples (15 cancer tissues and 15 adjacent tissues) were prepared for the cDNA microarray (MecDNA-HKidE030CS01, Shanghai Outdo Biotech Co., Ltd.) according to the manufacturer's instructions. Real-time PCR was performed using a $\mathrm{SYBR}^{\circledR}$ Premix Ex $\mathrm{Taq}^{\mathrm{TM}}$ II (Tli RNaseH Plus, RR820Q) in 96well reaction plates according to the manufacturer's instructions. The forward primer sequence was SMARCC1-F: 5'-TGAGGAGGATTATGAGGTGG-3', and the reverse primer sequence was SMARCC1-R: 5'-CGTGATTCTGTTGGTGTCG-3'. The PCR product length was $177 \mathrm{bp}$. $\beta$-Actin served as a reference gene, and the primers used were as follows: Human $\beta$-actin-F1: 5'-GAAGAGCTACGAGCTGCCTGA-3' Human $\beta$-actin 5'-CAGACAGCACTGTGTTGGCG-3'. The $\beta$-actin PCR product length was $191 \mathrm{bp}$.

Each sample was prepared in a total volume of $50 \mu \mathrm{L}$ containing $2 \mu \mathrm{L}$ of $0.4 \mu \mathrm{mol} / \mathrm{L}$ primer mix, $25 \mu \mathrm{L}$ SYBR Green master mix, $4 \mu \mathrm{L}$ DNA template, and $16 \mu \mathrm{L}$ RNase/ DNase-free sterile water. The initial denaturation was performed at $95^{\circ} \mathrm{C}$ for $30 \mathrm{~s}$, followed by 40 cycles at $95^{\circ} \mathrm{C}$ for $5 \mathrm{~s}$, and $60^{\circ} \mathrm{C}$ for $30 \mathrm{~s}$. The fluorescence data were collected in the $60^{\circ} \mathrm{C}$ extension phase.

\section{Statistical analysis}

The data of SMARCC1 expression in ccRCC tissues was analyzed by Npar Tests. The relationship between SMARCC1 expression and clinical factors was calculated using the Spearman rank correlation coefficient. The correlation between SMARCC1 expression and clinical data as well as the overall survival time was evaluated using the Kaplan-Meier method and the log-rank test. Finally, variables that were statistically significant in the univariate analysis were included in a Cox multivariate regression survival analysis. $\mathrm{P}<0.05$ was considered statistically significant. 

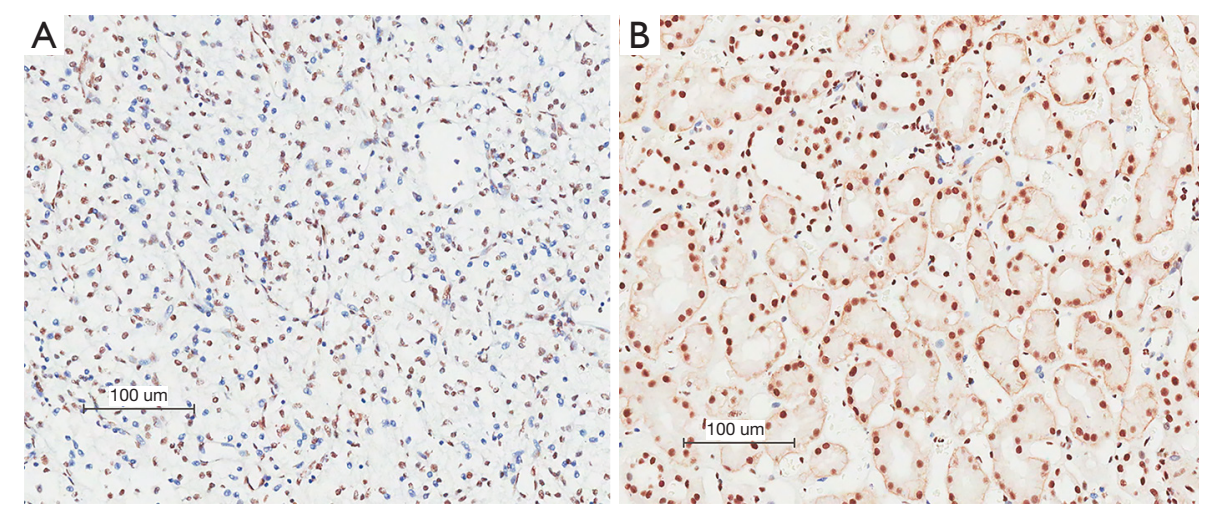

Figure 1 Representative immunohistochemistry images of SMARCC1 expression in clear cell renal cell carcinoma (ccRCC) (A) and paired para-tumor tissue samples (B).

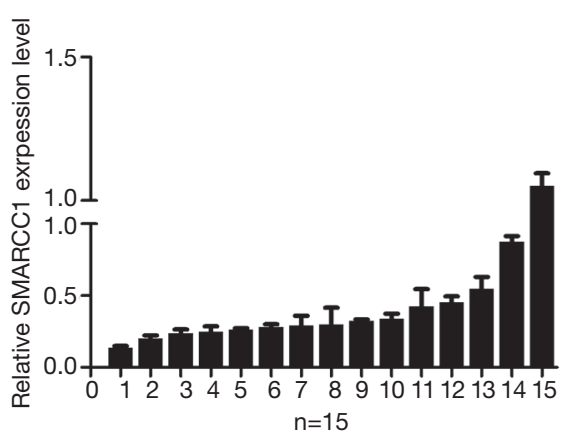

Figure $2{ }^{-\Delta \Delta C t}$ represents the multiple differences in gene expression in cancer and adjacent normal tissues: SMARCC1 was overexpressed in clear cell renal cell carcinoma (ccRCC) tissues if $2{ }^{\Delta \Delta \mathrm{Ct}}$ $>1$, whereas SMARCC1 was under-expressed when $2-^{\Delta \Delta \mathrm{Ct}}<1$.

\section{Results}

\section{SMARCC1 expression in ccRCC tissues was significantly lower than that in paired para-tumor tissues}

The expression of SMARCC1 in ccRCC tissues was significantly lower compared with their corresponding paired para-tumor tissues $(4.370 \pm 2.036$ vs. $6.167 \pm 1.162$, $\mathrm{P}=0.001$ ), especially in the cortex (Figure 1). Consistently, the result obtained from the ccRCC cDNA tissue microarray also showed that SMARCC1 mRNA expression in ccRCC tissues was significantly lower than that in paratumor tissues. The results were shown in detail in Figure 2.

\section{The expression of SMARCC1 was significantly correlated with high pathological grade}

The relationship between SMARCC1 expression and the clinical characteristics of the ccRCC patients, including gender, age, tumor size, pathological grade, TNM stage, and clinical stage, was analyzed. The results revealed a significant positive correlation between SMARCC1 expression and high pathological grade $(\mathrm{r}=0.224, \mathrm{P}=0.011)$. No significant link was found between SMARCC1 and age, gender, tumor size, $\mathrm{T}$ stage, $\mathrm{N}$ stage, or clinical stage. The results were shown in detail in Table 2.

\section{High SMARCC1 expression was correlated with a good prognosis in ccRCC}

The relationship between SMARCC1 expression and the overall survival of patients with ccRCC was analyzed. The results showed that patients with high SMARCC1 expression had a better prognosis than those with low SMARCC1 expression (80.6\% vs. 93.4\%, $\mathrm{P}=0.028)$. The results also showed that high SMARCC1 expression was correlated with a better prognosis compared with low SMARCC1 expression $(40.0 \%$ vs. $95.2 \%, \mathrm{P}=0.000)$ in the high pathological grade (grades III and IV), male (73.5\% vs. $95.3 \%, \mathrm{P}=0.004)$, and tumor size $>5 \mathrm{~cm}(62.5 \%$ vs. $89.5 \%$, $\mathrm{P}=0.044)$ sub-groups. The results were shown in detail in Figure 3.

Subsequently, the multi-factor survival analysis showed that SMARCC1 expression could serve as an independent predictive factor for ccRCC $(\mathrm{P}=0.008)$. The results of the analysis were shown in detail in Table 3.

\section{Discussion}

It has been reported that SMARCC1 plays a dual 
Table 2 The expression of SMARCC1 is significantly correlated with pathological grade

\begin{tabular}{|c|c|c|c|c|c|c|c|}
\hline Variable & Gender & Age & Pathological grade & Tumor size & $\mathrm{T}$ & $\mathrm{N}$ & Clinical stage \\
\hline Sig. (2-tailed) & 0.782 & 0.151 & 0.011 & 0.358 & 0.816 & 0.838 & 0.816 \\
\hline $\mathrm{N}$ & 128 & 128 & 128 & 128 & 128 & 128 & 128 \\
\hline
\end{tabular}

*, $\mathrm{P}<0.05$.
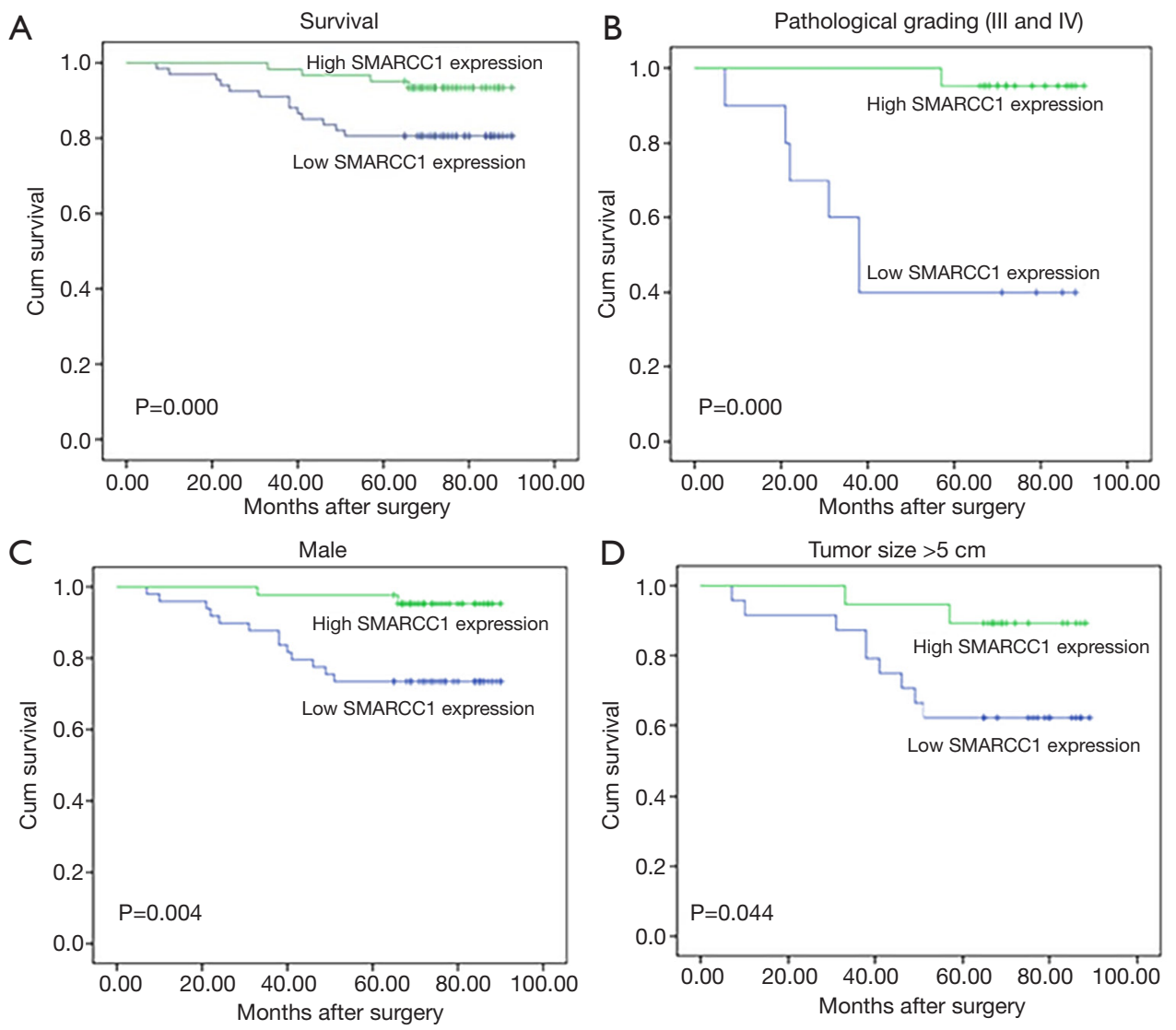

Figure 3 Overall survival analysis according to different SMARCC1 expression levels: (A) all the patients; (B) the sub-group of high pathological grade (III and IV); (C) male sub-group; (D) the sub-group of tumor size $>5 \mathrm{~cm}$.

regulatory role of oncogene and tumor suppressor in cancer $(12,13)$. SMARCC1 expression is up-regulated in prostate cancer and is positively correlated with tumor recurrence and differentiation (14). Moreover, the arginine methyltransferase CARM1 targets SMARCC1 to promote tumor progression and metastasis. However, higher SMARCC1 expression was found to be significantly correlated with a better overall survival in both colorectal cancer and prostate cancer $(4,15)$.

Our study primarily investigated the expression of
SMARCC1 and its clinical importance using microarrays of two common histological types of ccRCC (HKidE180Su02 and MecDNA-HKidE030CS01). The results showed that the expression of SMARCC1 was significantly decreased in ccRCC tissues and that SMARCC1 expression was significantly correlated with high pathological grade $(\mathrm{r}=0.224, \mathrm{P}=0.011)$. High SMARCC1 expression was correlated with a better prognosis compared with lower SMARCC1 expression $(40.0 \%$ vs. $95.2 \%, \mathrm{P}=0.000)$ in the high pathological grade (grades III and IV), male (73.5\% 
Table 3 SMARCC1 expression serves as an independent predictive factor for clear cell renal cell carcinoma (ccRCC)

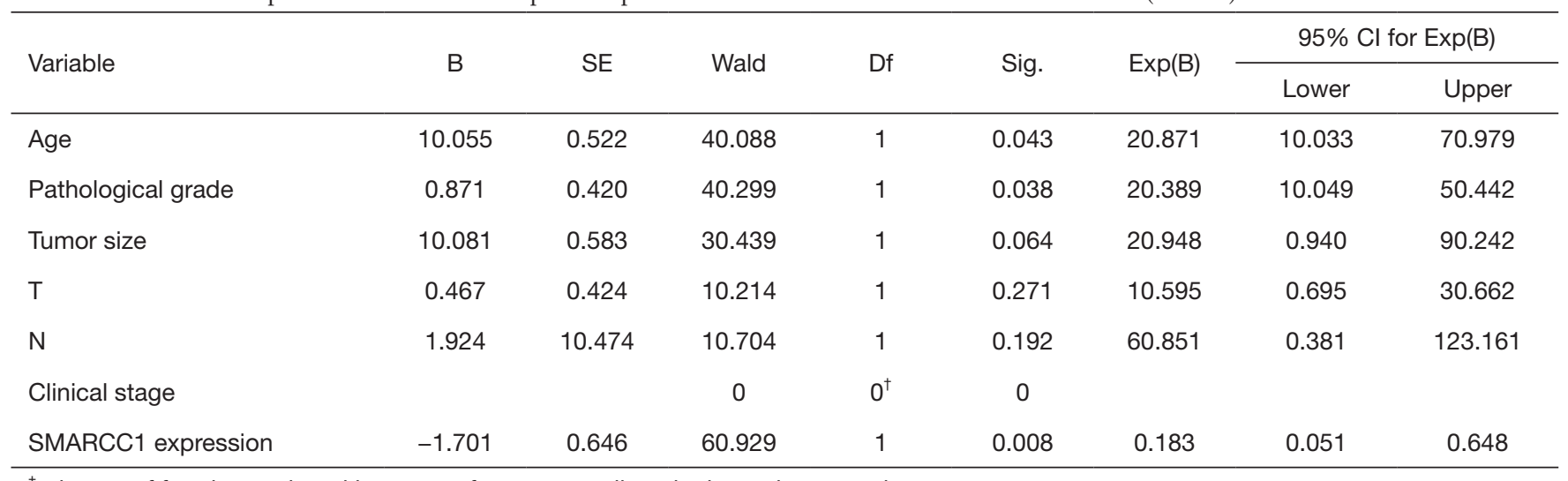

${ }^{\dagger}$, degree of freedom reduced because of constant or linearly dependent covariates.

vs. $95.3 \%, \mathrm{P}=0.004)$, and tumor size $>5 \mathrm{~cm}(62.5 \%$ vs. $89.5 \%, \mathrm{P}=0.044)$ sub-groups, which is consistent with the database (https://www.proteinatlas.org) that shows that renal cancer patients with high SMARCC1 expression have a significantly better 5 -year prognosis.

In conclusion, our study revealed that SMARCC1 expression was significantly decreased in ccRCC tissues, and that SMARCC1 expression was significantly correlated with pathological grade. Compared with lower SMARCC1 expression, high SMARCC1 expression was correlated with a better prognosis. Future studies are needed to explain the mechanism of the occurrence and progression of ccRCC.

\section{Acknowledgments}

Funding: This work was supported by grant from National Natural Science Funds of China (Multidimensional evaluation and mechanism research on iNSCs transplantation for cerebral nerve repair in $\mathrm{AD}$ mice, No. 81571655).

\section{Footnote}

Reporting Checklist: The authors have completed the REMARK reporting checklist. Available at http://dx.doi. org/10.21037/tau-20-935

Data Sharing Statement: Available at http://dx.doi. org/10.21037/tau-20-935

Peer Review File: Available at http://dx.doi.org/10.21037/ tau-20-935
Conflicts of Interest: All authors have completed the ICMJE uniform disclosure form (available at http://dx.doi. org/10.21037/tau-20-935). QD serves as an unpaid editorial board member of Translational Andrology and Urology from Mar 2012 to Feb 2022. The other authors have no conflicts of interest to declare.

Ethical Statement: The authors are accountable for all aspects of the work in ensuring that questions related to the accuracy or integrity of any part of the work are appropriately investigated and resolved. The study was conducted in accordance with the Declaration of Helsinki (as revised in 2013). Informed consent was obtained, and the study was approved by The Ethics Boards of Huashan Hospital (No.2020-529). All experiments were carried out in accordance with institutional guidelines. Written informed consent was obtained from the patients undergoing surgery.

Open Access Statement: This is an Open Access article distributed in accordance with the Creative Commons Attribution-NonCommercial-NoDerivs 4.0 International License (CC BY-NC-ND 4.0), which permits the noncommercial replication and distribution of the article with the strict proviso that no changes or edits are made and the original work is properly cited (including links to both the formal publication through the relevant DOI and the license). See: https://creativecommons.org/licenses/by-nc-nd/4.0/.

\section{References}

1. Hsieh JJ, Purdue MP, Signoretti S, et al. Renal cell carcinoma. Nat Rev Dis Primers 2017;3:17009.

2. Schaniel C, Ang YS, Ratnakumar K, et al. Smarcc1/Baf155 
couples self-renewal gene repression with changes in chromatin structure in mouse embryonic stem cells. Stem Cells 2009;27:2979-91.

3. DelBove J, Rosson G, Strobeck M, et al. Identification of a core member of the SWI/SNF complex, BAF155/ SMARCC1, as a human tumor suppressor gene. Epigenetics 2011;6:1444-53.

4. Hansen RL, Heeboll S, Ottosen PD, et al. Smarcc1 expression: a significant predictor of disease-specific survival in patients with clinically localized prostate cancer treated with no intention to cure. Scand J Urol Nephrol 2011;45:91-6.

5. Ke SB, Qiu H, Chen JM, et al. MicroRNA-202-5p functions as a tumor suppressor in colorectal carcinoma by directly targeting SMARCC1. Gene 2018;676:329-35.

6. Iwagami Y, Eguchi H, Nagano H, et al. miR-320c regulates gemcitabine-resistance in pancreatic cancer via SMARCC1. Br J Cancer 2013;109:502-11.

7. Gupta K, Miller JD, Li JZ, et al. Epidemiologic and socioeconomic burden of metastatic renal cell carcinoma (mRCC): a literature review. Cancer Treat Rev 2008;34:193-205.

8. Wang Y, Wan F, Chang K, et al. NUDT expression is predictive of prognosis in patients with clear cell renal cell carcinoma. Oncol Lett 2017;14:6121-8.

9. Rabjerg M, Bjerregaard H, Halekoh U, et al. Molecular characterization of clear cell renal cell carcinoma

Cite this article as: Wang G, Lv Q, Ma C, Zhang Y, Li H, Ding Q. SMARCC1 expression is positively correlated with pathological grade and good prognosis in renal cell carcinoma. Transl Androl Urol 2021;10(1):236-242. doi: 10.21037/tau-20-935 identifies CSNK2A1, SPP1 and DEFB1 as promising novel prognostic markers. APMIS: Acta Pathologica, Microbiologica, Et Immunologica Scandinavica 2016;124:372-83.

10. Baldewijns MM, van Vlodrop IJ, Schouten LJ, et al. Genetics and epigenetics of renal cell cancer. Biochimica Et Biophysica Acta 2008;1785:133-55.

11. Vera-Badillo FE, Templeton AJ, Duran I, et al. Systemic therapy for non-clear cell renal cell carcinomas: a systematic review and meta-analysis. Eur Urol 2015;67:740-9.

12. Agaimy A, Amin MB, Gill AJ, et al. SWI/SNF protein expression status in fumarate hydratase-deficient renal cell carcinoma: immunohistochemical analysis of 32 tumors from 28 patients. Hum Pathol 2018;77:139-46.

13. Wang L, Zhao Z, Meyer MB, et al. CARM1 methylates chromatin remodeling factor baf155 to enhance tumor progression and metastasis. Cancer Cell 2016;30:179-80.

14. Heeboll S, Borre M, Ottosen PD, et al. SMARCC1 expression is upregulated in prostate cancer and positively correlated with tumour recurrence and dedifferentiation. Histol Histopathol 2008;23:1069-76.

15. Andersen CL, Christensen LL, Thorsen K, et al. Dysregulation of the transcription factors SOX4, CBFB and SMARCC1 correlates with outcome of colorectal cancer. Br J Cancer 2009;100:511-23. 